\title{
Electrical property of laser-sintered nanopastes with reduced metal nanoparticles prepared by laser ablation in liquids
}

\author{
Taku Saiki*, Yukio Iida, Kennan Ri, Marina Yoshida, Yuuki Koga \\ Department of Electrical and Electronic Engineering, Faculty of Engineering Science, Kansai University, 3-3-35 Yamate, Suita, Osaka, Japan
}

\section{Email address:}

tsaiki@kansai-u.ac.jp (T. Saiki)

\section{To cite this article:}

Taku Saiki, Yukio Iida, Kennan Ri, Marina Yoshida, Yuuki Koga. Electrical Property of Laser-Sintered Nanopastes with Reduced Metal Nanoparticles Prepared by Laser Ablation in Liquids. Advances in Materials. Vol. 3, No. 6, 2014, pp. 75-83. doi: 10.11648/j.am.20140306.13

\begin{abstract}
Reduced iron, aluminum, copper, and magnesium nanoparticles were produced from iron oxide $\left(\mathrm{Fe}_{3} \mathrm{O}_{4}\right)$, aluminum oxide $\left(\mathrm{Al}_{2} \mathrm{O}_{3}\right)$, copper oxide $(\mathrm{CuO})$, and magnesium oxide $(\mathrm{MgO})$ powders by using laser ablation in liquids, and nanopastes were synthesized with the reduced iron, aluminum, copper, and magnesium nanoparticles. The nanopastes were sintered by using a continuous-wave fiber laser in air atmosphere. The laser-sintered nanopastes consist of polycrystalline metal. The structures of the laser-sintered metal nanopastes were analyzed by SEM and EDX, and their resistivities were evaluated by four-terminal method. The metal nanopastes sintered by hot plate have 2.5- to 11-times-higher resistivities than those of common metals fabricated in blast furnaces. Moreover, the laser-sintered metal nanopastes have 9.5- to 45-times-higher resistivities than those of common metals fabricated in blast furnaces.
\end{abstract}

Keywords: Polycrystalline Metal, Laser Sintering, Metal Nanopaste, Laser Ablation in Liquids

\section{Introduction}

Additive manufacturing is promising because it can fabricate free-form structures easily. This instrument uses a technology called "selective laser sintering" (SLS) [1]. SLS uses a high-power laser, such as a $\mathrm{CO}_{2}$ laser, a fiber laser, or laser diodes, to sinter some kinds of powders. Plastic, ceramic, glass, and metals are typically used as powders (with diameters of a few tens of micrometers) for SLS. While, a technology for producing small electrical circuits at low cost, called "printed electronics," by using "metal-nanoparticle ink" or "nanopastes" has been developed $[2,3]$. The nanopastes or nanoparticle inks which are composed of highly doped metal nanoparticles can be sintered at low temperatures by exploiting the degradation of the melting points of metal powders. Here, we can obtain special metals, which are metal plates with nano-sized polycrystals. On the basis of this surface-energy reduction, metal plates with nano-sized polycrystals can be formed. The polycrystalline metals are often organized. The melting point of the metal nanoparticles is $14 \%$ to $30 \%$ of that of the metal bulks. The melting temperatureis usually between 373 and $473 \mathrm{~K}$. Gold or silver nanoparticle ink or nanopastes are used in electrical circuits because gold and silver are difficult to oxidize. These pastes, however, are expensive, so copper nanopaste or copper-nanoparticle inks (which are lower cost) have been researched [4-6]. Moreover, copper nanoparticle ink or copper nanopastes oxidize easily under sintering, and the sintered metals have high resistivities [5]. Copper nanoparticle ink or copper nanopastes sintered by laser with low resistivity can be produced under a narrow laser-intensity regime [5] or a reducing atmosphere by using nitrogen gas [4]. Moreover, a pulse laser or a flash lamp was used for sintering to prevent oxidization of copper. Preparing copper nanopastes with high quality is very hard, and they have high material cost. Thus, a method for sintering metals that are easy to oxidize needs complicated procedures. Normally, metal nanopastes mainly consist of metal nanoparticles with a coating to protect against oxidation and condensation. Pure nanoparticles with average diameter from ten to one-hundred nanometers have a very high reactivity to oxidize in atmosphere easily. Accordingly, they are hard to deal with.

In addition, low-cost nanopastes are needed for SLS or printed electronics. It is costly to prepare pure-metal particles 
as metal nanopastes for SLS or printed electronics. The high material cost of pure metals is mainly owing to the fact that the process of preparing pure metals from metal oxides consumes a large amount of energy. Metal oxides thus have lower material costs than that of pure metal. If pure-metal nanoparticles were made by reducing metal oxide powders, and the reduced metal nanoparticless were used for metal nanopastes or nanoparticle inks, the material cost could be gradually reduced. However, metal oxide powders are reduced to pure-metal powders by electrolysis and microwave or plasma irradiation at high temperature (over $10,000 \mathrm{~K})$, and it is normal to use a large amount of electricity and some chemicals. Especially in the case of electrolysis, hazardous gas is generated by the reduction process. Reduced metal particles produced by the conventional method thus have high cost.

Reduction of metal oxides using pulsed laser with a high-peak-power in liquids by low cost has been already performed. Metal oxides have already been reduced at low cost by using a pulsed laser with a high peak power in liquids [7-15]. This method uses a special mechanism for the reduction. Usually, thermal reduction occurs during irradiation by microwaves or plasma at high temperature. However, it has been suggested that this process not only involves thermal reduction but also coulomb explosion due to electrons being ejected from metal oxides. Until now, because this method used low repetition-rate lasers with high-energy pulses, the efficiency of reduction by laser irradiation is around $60 \%$, and the amount of reduced metal nanoparticles that are produced is small. We modified this method by using a highly repetitive nanosecond-pulse laser. If the repetition rate is over $1 \mathrm{kHz}$, the reduction efficiency is reported to be close to $100 \%[12,13,15]$. The amount of reduced metal nanoparticles produced by using this modified method is very large. Moreover, the energy required to reduce metal oxides is considerably lower than that consumed by other methods because of the special mechanism outlined above.

We previously proposed an energy cycle using solar-pumped pulse lasers and metals [12-15]. Metal air cells generate electricity from the reaction of a metal with oxygen $[12,13]$. Metal oxides are produced after the metals are used for generating electricity. They are reduced by using a pulse laser generated from solar power. As recyclable metals in this energy cycle, iron, aluminum, and magnesium have been already used. Sintered iron [12], aluminum [12], and magnesium [13] nanopastes have been already used for the air fuel cells. We have already developed and successfully demonstrated a small instrument for producing metal nanoparticles by using a solar-pumped high-repetition-rate pulse laser. The instrument can be used to produce a large amount of metal nanoparticles from metal oxides at a very low cost.

Nanocrystalline metals have already been fabricated by using a fast-cooling method and a "strong-distortion processing method" and their mechanical and electrical properties have been measured [16,17]. These nanocrystalline metals have been applied in small electrical circuits, connection wires, and magnetic substances. The electrical and magnetic properties of nanocrystalline metals are remarkably different from those of the bulk metal prepared in a conventional melting furnace because phonon transfer is prevented. It is thus expected that the abilities of electrical or magnetic devices will be improved by using nanocrystalline metals in the future.

At this time, large amounts of iron, aluminum, copper, and magnesium nanoparticles were prepared (with high reduction efficiency) from $\mathrm{Fe}_{3} \mathrm{O}_{4}, \mathrm{Al}_{2} \mathrm{O}_{3}, \mathrm{CuO}$, and $\mathrm{MgO}$ powders by using laser ablation in liquids, and nanopastes were formed with the produced metal nanoparticles. Normally, it was very hard to produce iron, aluminum, copper, and magnesium nanopastes owing to oxidization, and to the authors' knowledge, nanopastes other than those developed by us have not been reported. In the present study, a high-repetitive-rate nanosecond pulse laser was used for laser ablation in liquids. The produced nanopastes were sintered using a CW fiber laser in air atmosphere, and iron, aluminum, copper, and magnesium metal plates (with centimeter-order size and low electrical resistance) were obtained. Moreover, the structures of the sintered metal nanopastes were observed by SEM and EDX, and their volume resistivities were evaluated, and the volume resistivities were also compared with those of the normal bulk metals. Except those developed in the present study, laser-sintered nanopastes composed of such metal-oxide powders reduced by laser ablation in liquids have not been reported. Furthermore, we can produce large-scale sintered metal plates or bulk metals at high speed and low cost if high-power lasers are used.

\section{Preparation of Metal Nanopastes}

A high-repetition-rate microchip Nd:YAG pulsed laser was used for preparing the metal nanopastes. Maximum output average laser power was $250 \mathrm{~mW}$, laser wavelength was $1064 \mathrm{~nm}$, repetition rate of the laser pulses was $18 \mathrm{kHz}$, and pulse duration was $8 \mathrm{~ns}$. The laser beam, with a diameter of 6 $\mathrm{mm}\left(1 / \mathrm{e}^{2}\right)$, was focused by using a lens with a focal length of $50 \mathrm{~mm}$. The diameter of the focused beam was thus $20 \mu \mathrm{m}$ at the front of glass bottle. Glass bottles (with a diameter of 20 $\mathrm{mm}$ and length of $38 \mathrm{~mm}$ ) were used in this experiment. Metal oxide particles were confined in the glass bottles (with volume of $5 \mathrm{~mL}$ ) and reduced by using pulsed laser ablation in pure water. Iron oxide $\left(\mathrm{Fe}_{3} \mathrm{O}_{4}\right)$, aluminum oxide $\left(\alpha-\mathrm{Al}_{2} \mathrm{O}_{3}\right)$, copper oxide $(\mathrm{CuO})$, and magnesium oxide $(\mathrm{MgO})$ (Kounjyundo Chemical Co., Ltd., Japan) were respectively reduced to iron, aluminum, copper, and magnesium (all with purity of $99.9 \%$ ). The weight of all the metal oxides used in this preparation procedure was $1.0 \mathrm{~g}$. For an example, reduced aluminum nanoparticles by using this method are shown in Fig. 1. The left side in Fig.1 shows the aluminum metal oxides after laser irradiation. The color of the powder was changed to gray. According to experimental results on hydrogen generation $[12,13,15]$, it has been cleared that aluminum powder after laser irradiation was almost reduced 
completely. A similar result was reported in the case of iron powder reduced by laser irradiation [15]. As a consequence, the metal nanoparticles have oxide shells. However, the oxide shells do not affect the laser sintering because they are very thin. This reduction method produces metal nanoparticles. Moreover, the bandwith of the X-ray spectrum obtained by XRD analysis of the metal nanoparticles indicates that their mean sizes are a few tens of nanometers. According to XRD analysis, the mean size of the reduced magnesium nanoparticles is $6 \mathrm{~nm}$ [13]. Morevover, it has been found from the results that metal hydroxide is generated on the surface of the reduced magnesium nanoparticles only in the case of the laser irradiation of the magnesium-oxide power. The generated $\mathrm{Mg}(\mathrm{OH})_{2}$ does not adversely affect the preparation of the mangesium nanopastes.

The reduced metal powders were mixed in a silver paste (NAG10 Ag 82 wt.\%; Daiken Chemical Co. Ltd., Japan) with a weight of $25 \mathrm{mg}$. The mixed powder was changed to clay. The oxides on the surface of the metal nanoparticles were removed, and the metal nanoparticles were incorporated in coordinate bond. The incorporated metal nanoparticles thus became stable and dispersed. The prepared metal pastes were pasted on slide glasses. The width of the metal pastes on the glasses were all $7 \mathrm{~mm}$, the thickness was $50 \mu \mathrm{m}$, and the length was around $20 \mathrm{~mm}$. The size of the slide glass was $2.3 \times 3.6 \mathrm{~cm}$ with thickness of $1.5 \mathrm{~mm}$. In the case of the iron nanopaste, reduced iron with a weight of around $90 \mathrm{mg}$ was mixed in the silver paste. Some commercially available nanopastes available were sintered to compare these iron and aluminum pastes.

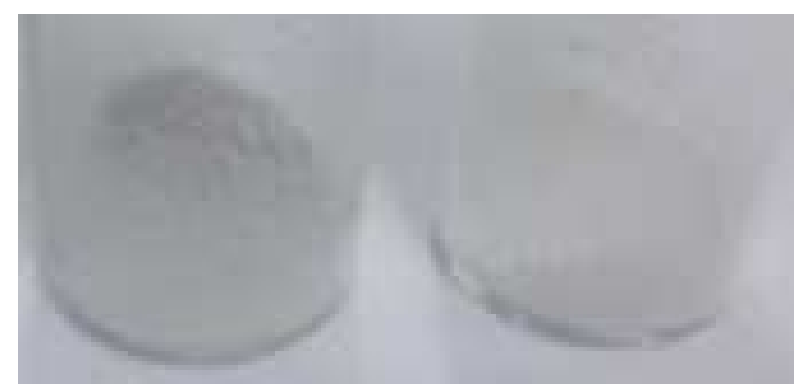

Fig. 1. Reduced Al nanoparticles; left: after irradiating pulse laser, right: $\mathrm{Al}_{2} \mathrm{O}_{3}$ powder.

\section{Experimental Setup for Laser Sintering}

A continuous-wave (CW) Yb:fiber laser (Furukawa Electric, Japan) was used for laser sintering. The fiber laser has a high electricity-optical conversion efficiency and uses air cooling. As for the wavelength and output power of the laser used for laser sintering, a laser with a wavelength in the violet-to-far-infrared regime and output power of a few watts was commonly used. In the case of that regime, metal nanopaste can absorb almost all the laser light when the laser light was irradiated on it. The maximum output laser power was $6 \mathrm{~W}$. The diameter of the output laser beam was $6 \mathrm{~mm}$ $\left(1 / \mathrm{e}^{2}\right)$. A Yb:fiber laser with a wavelength of $1064.1 \mathrm{~nm}$ was used because that wavelength is the same as that of a $\mathrm{Nd} / \mathrm{Cr}$ :YAG ceramic laser. The $\mathrm{Nd} / \mathrm{Cr}$ :YAG ceramic is employed in solar-pumped laser [14]. The experimental setup for laser sintering is shown schematically in Fig. 2.

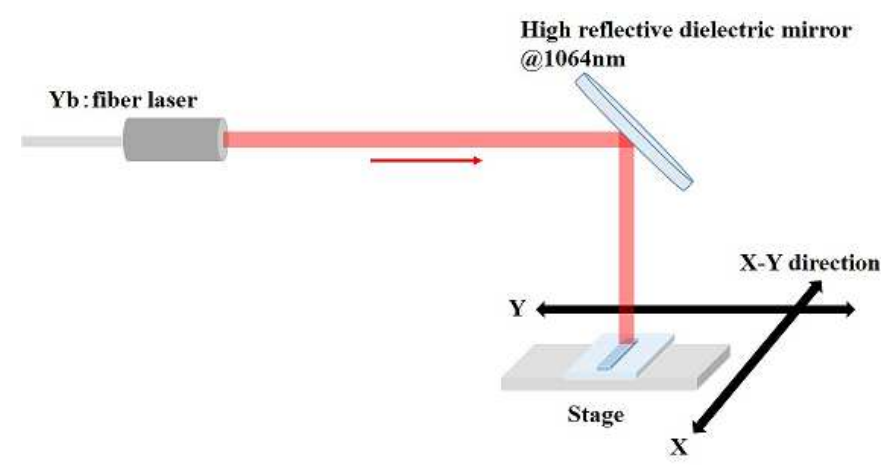

Fig. 2. Experimental setup for laser sintering.

When the metal nanopastes were sintered, the laser beam was fixed, and the stage was moved in the $\mathrm{X}$ and $\mathrm{Y}$ directions. The metal nanopastes were applied directly to the glass plates on the stage and then sintered in air atmosphere.

The laser parameters were chosen as described below. The laser beam was scanned over the metal nanopastes once in the $\mathrm{X}$ direction by moving one of the mechanical stages shown in Fig. 2. After the scan, the laser beam was moved scanned in the $\mathrm{Y}$ direction by moving the other mechanical stage. The scans in the $\mathrm{X}$ and $\mathrm{Y}$ directions were then repeated. The interval between the laser scans in the Y direction in was chosen to $1.0 \mathrm{~mm}$. The metal nanopastes were sintered by direct laser sintering and thermal conduction under this condition. When the interval between laser scans was set to over $2 \mathrm{~mm}$, the metal nanopastes ware not sintered uniformly. Here, the scan rate of the laser beam was set to $0.25 \mathrm{~mm} / \mathrm{s}$. The laser intensity was estimated to be $9 \mathrm{~W} / \mathrm{cm}^{2}$, and all the sintered metal nanopastes showed low resistance when output laser power was over $2.0 \mathrm{~W}$. The laser power at which low resistance can be obtained by laser sintering varies slightly in accordance with each metal nanopaste. The metal nanopastes were heated to over $473 \mathrm{~K}$, at which, the metal powders cannot be melted. After the laser sintering, the thin surfaces of the sintered metal nanopastes were removed, and metallic lusters appear on the sintered metal pastes.

To compare the electrical properties, the laser sintered iron, aluminum, copper, and magnesium pastes, silver and copper nanopastes (Daiken Chemical Co. Ltd., Japan), which are commercial products, were also used for laser sintering. The structure of the laser-sintered metal nanopastes were observed by an S-4700 scanning electron microscope (SEM) (Hitachi High Technologies, Japan). An EMAX7000 energy-dispersive X-ray spectrometry (EDX) (Horiba, Japan) was used for analyzing the distributions of silver, mixed metal, oxides, and impurities. The resistances of the sintered metal nanopastes were evaluated by the four-terminal method, and their volume resistivities were estimated. To compare the volume resistivities, we showed the results of the sintered metal pastes sintered by hot plate. The hot plate used keeps a 
constant temperature by means of an electrical controller, and the maximum temperature of the hot plate can be set to 773 $\mathrm{K}$. The resistivities were also compared with those of the normal bulk metals.

\section{Results and Discussion}

The results of the experimental evaluations of the sintered metal pastes are shown as follows. After laser irradiation, the metal nanopastes were heated to over $473 \mathrm{~K}$, the additional heating reaction of metal nanopastes when sintering occurs actively. When the sintering reaction occurs, metal paste looks like a melted metal in the dark. The color of the sintering metal paste changed to orange. It has been thought from the color that the temperature of the metal paste reaches over $1500 \mathrm{~K}$. The results of the experiment show that iron, aluminum, copper, and magnesium nanopastes were sintered successfully.

\subsection{Photo Images of Sintered Metal Paste}

The hot-plate sintered metal pastes and the laser-sintered metal pastes are shown in Fig. 3. A sintered commercial silver nanopaste sintered by hot plate is shown in Fig. 3(a). The silver paste was sintered at $523 \mathrm{~K}$ for five minutes. A copper nanopaste sintered by hot plate is shown in Fig. 3(b). The nanopaste was made by mixing large amount of pure copper metal powders (with mean diameter of $5 \mu \mathrm{m}$ ) with silver paste. The prepared copper paste was sintered at $473 \mathrm{~K}$ for one minute and $523 \mathrm{~K}$ for five minutes. As a result, a pale red copper metal plate with very less oxidization was obtained by the sintering. Only the prepared magnesium paste was sintered at $473 \mathrm{~K}$ for one minute $573 \mathrm{~K}$ for five minutes. The laser-sintered metal pastes are shown in Figs. 3(c), (d), (e), and (f). Copper nanopastes (Daiken Chemical Co. Ltd., Japan) were sintered by the $\mathrm{CW}$ fiber laser (with output power of 2.5W). The laser-sintered paste is shown in Fig. 3(c). Laser scan rate was $0.6 \mathrm{~mm} / \mathrm{s}$. The copper nanopastes have a high resistance, namely, around $80 \Omega / \mathrm{cm}$. It has been prospected that the copper nanoparticles were hardly oxidized. The laser-sintered iron, aluminum, and copper nanopastes are shown in Figs. 3(d), (e), and (f), respectively. The output laser power of the $\mathrm{CW}$ fiber laser was $2.5 \mathrm{~W}$. The scan speed of the laser beam was $0.25 \mathrm{~mm} / \mathrm{s}$. As shown in these figures, metallic lusters appear on the sintered iron, aluminum, and copper nanopastes. It has been confirmed that the color of sintered copper paste in Fig. 3(b) and that of the sintered copper paste in Fig. 3(f) are remarkably different. It has been thought that the mean size of the copper particles in the sintered paste shown in Fig. 3(b) is order of few microns. In contrast, because the mean size of the copper polycrystals in the sintered paste shown in Fig. 3(f) is small (in the order of 10 $\mathrm{nm}$ ), it has been prospected that the spectrum of the reflected white light broadens owing to the activation of the plasmon on the surface of the sintered metal paste.

Commonly, the sintered iron paste is ferromagnetic. It has been also found that the sintered aluminum, copper, and magnesium pastes became ferromagnetic. These pastes were therefore attracted to a magnet easily. It has also been was also found that a sintered magnesium paste cannot burn easily contrary to normal magnesium powder or a magnesium plate [13].

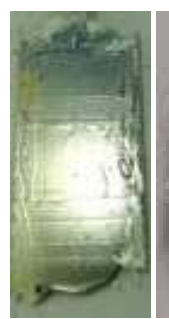

(a)

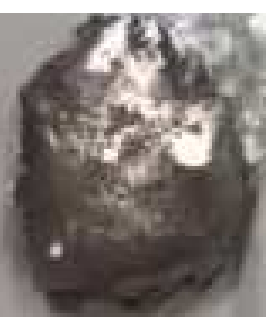

(b)

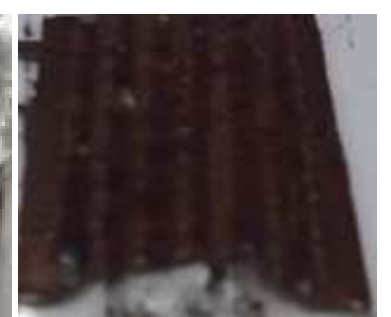

(c)

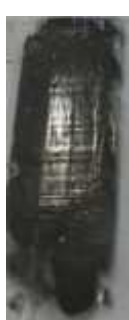

(d)

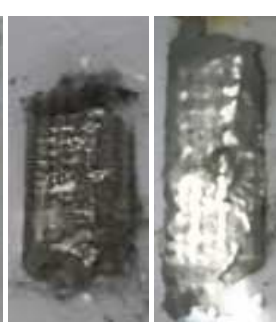

(e) (f)
Fig. 3. Each sintered metal pastes: (a) sintered Ag nanopaste; (b) sintered $\mathrm{Cu}$ nanopaste; (c) laser-sintered $\mathrm{Cu}$ nanopaste; (d) laser-sintered Fe plate; (e) laser-sintered Al plate; (f) laser-sintered Cu plate.

\subsection{SEM Images and Characteristic X-Ray Spectrum}

SEM images and the characteristic X-ray spectrum of the laser-sintered metal nanopastes with containing laser-reduced metal nanoparticles highly are shown in Figs. 4, 5, and 6. The results of analyzing components are shown in the next section. According to the results of EDX [shown in section 4.3], a characteristic X-ray spectrum [shown in Fig. 4(b)], and the results of XRD analysis [12], the large particles, which appear ball-like, consist of iron nanoparticles [12,15]. The large iron particles are secondary particles. As shown in Fig. 4(a), the reduced iron nanoparticles (with mean size of $12 \mathrm{~nm}$ ) were gathered and slicked together. The mean size of the grown iron particles was around $2 \mu \mathrm{m}$. It is clear that the large iron particles and silver sintered paste were separated. The characteristic X-ray spectrum of laser-sintered metal nanopastes was mainly observed for the secondary metal particles in the sintered metal pastes. Because the intensity of the characteristic X-ray spectrum differs according to material, such as metal, oxygen, or carbon, the quantities of such materials cannot be obtained. 


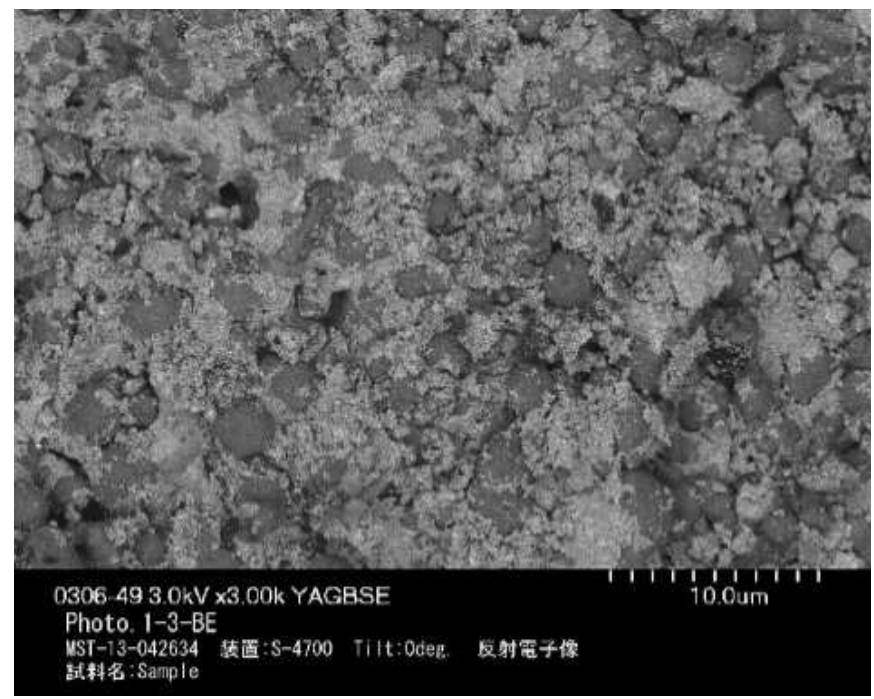

(a)

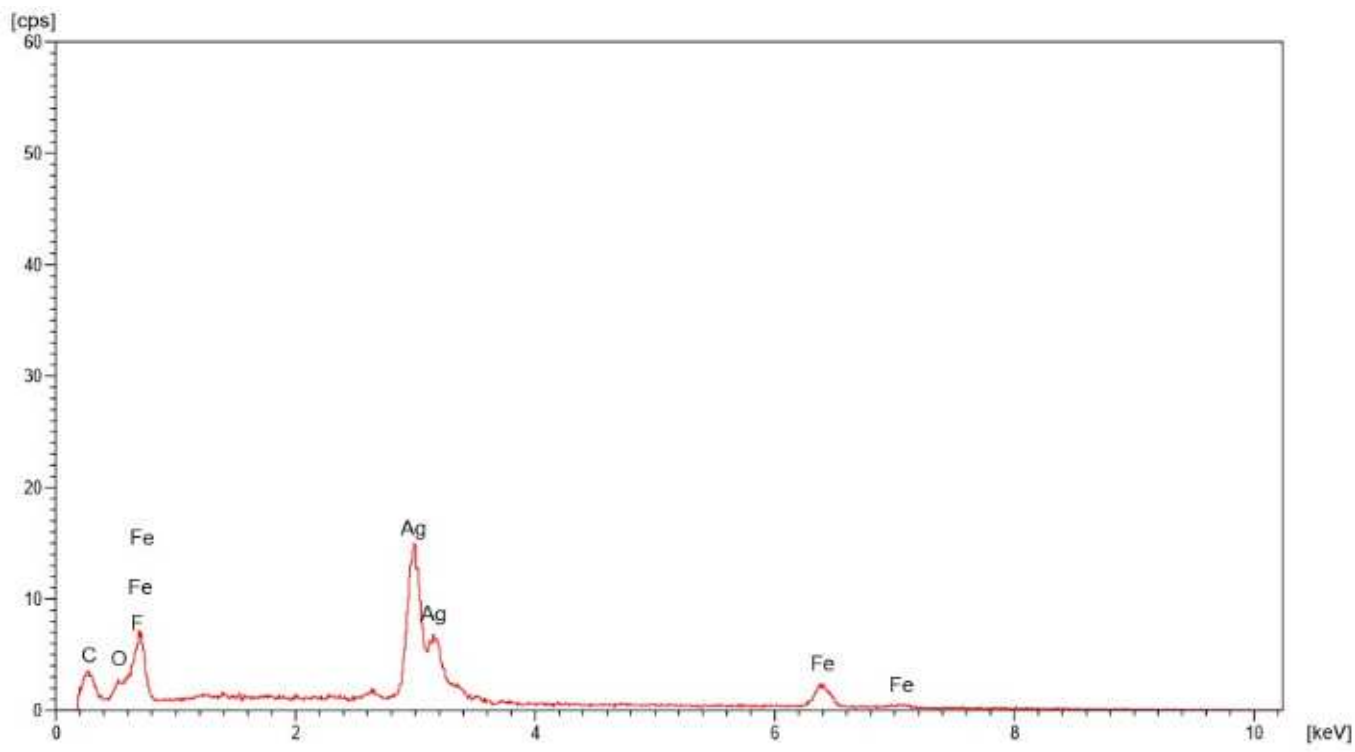

(b)

Fig. 4. Results of SEM analysis of laser-sintered Fe nanopaste: (a) image and (b) characteristic X-ray spectrum

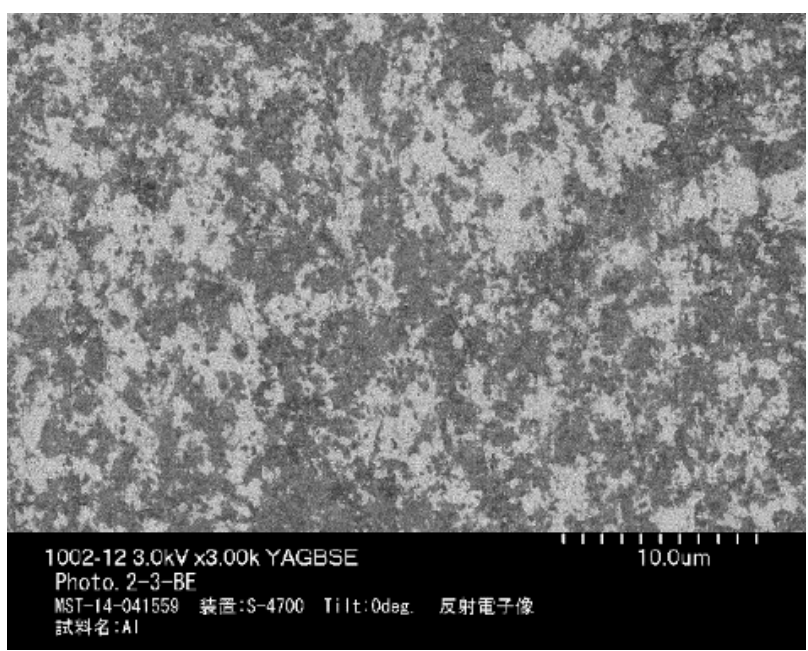

(a) 


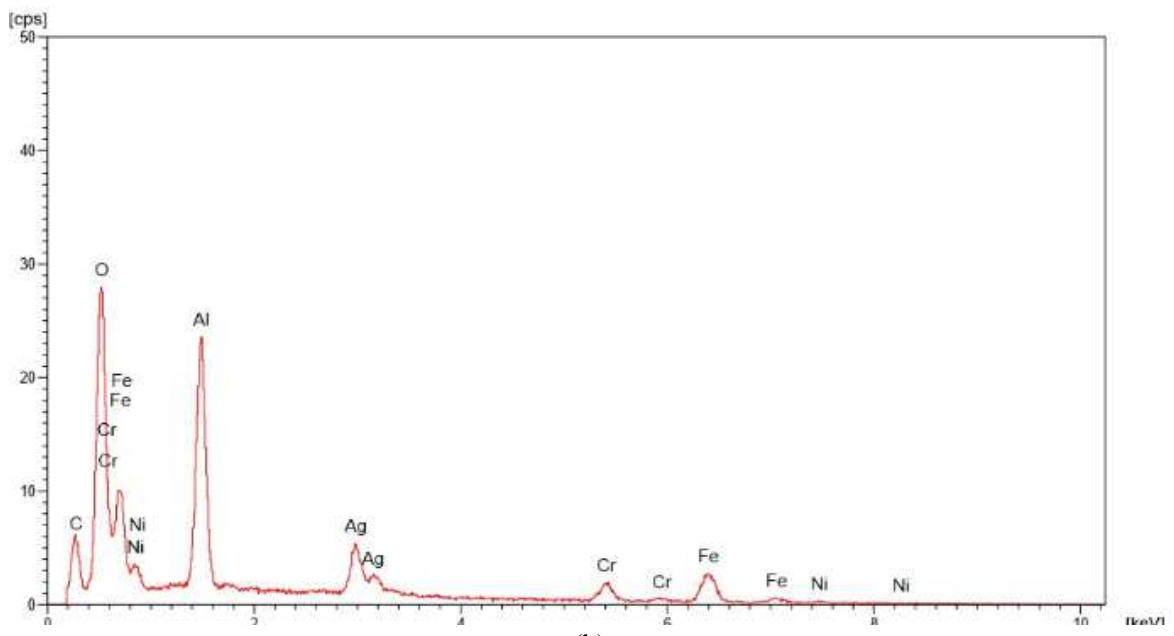

(b)

Fig. 5. Results of SEM analysis of laser-sintered Al nanopaste: (a) image and (b) characteristic X-ray spectrum

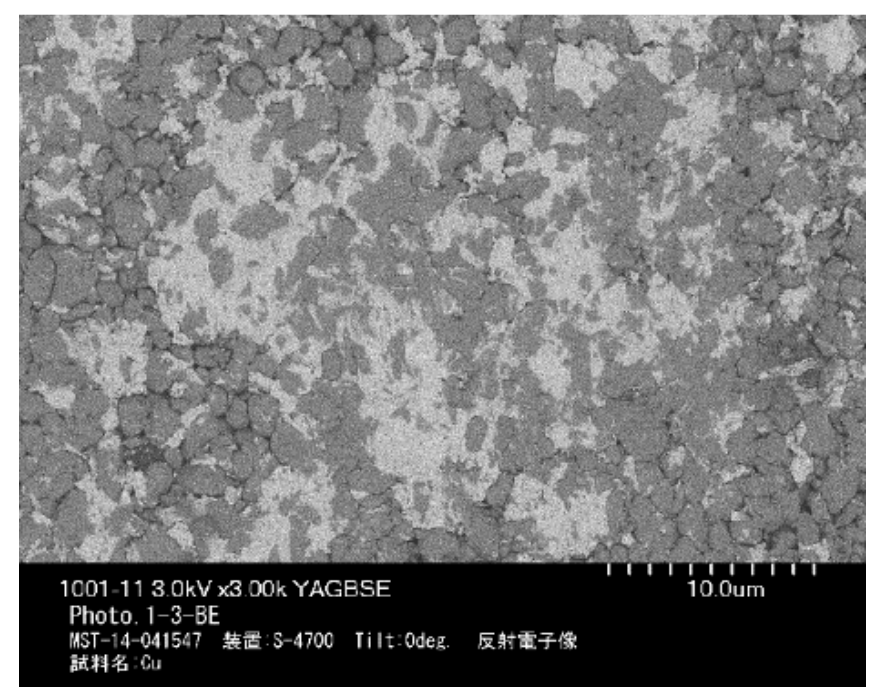

(a)

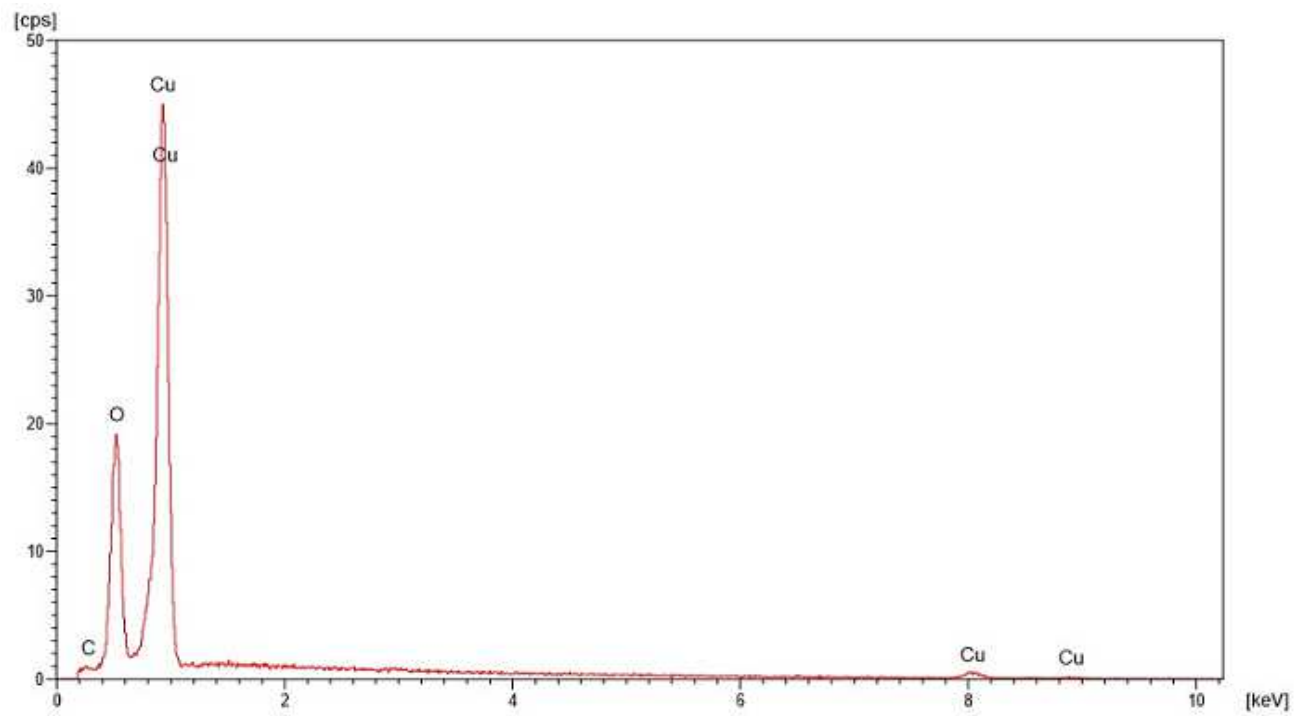

(b)

Fig. 6. Results of SEM analysis for laser-sintered Cu: (a) image and (b) characteristic X-ray spectrum 
The aluminum nanoparticles in the paste are gathered and stickled together. However, the mean size of the generated secondary aluminum particles was $0.5 \mu \mathrm{m}$ as shown in Fig. $5(\mathrm{a})$, which is smaller than that of the laser-sintered copper and iron nanopastes. The large aluminum particles and silver sintered paste were separated. It had been found from the SEM image that nano-order small structures exist on the surface of the secondary aluminum particles. According to the characteristic X-ray spectrum shown in Fig. 5(b), chromium, iron, and nickel were detected in the secondary aluminum particles. However, the ratio of all the impurity was in the order of $0.001 \%$ in the metal oxides before laser irradiation. This impurity content is not a problem in regard to fabricating pure metals plates. The metal impurities exist mainly in the secondary aluminum particles.

The copper nanoparticles in the paste are gathered and stickled together. The mean size of the generated secondary copper particles was 1.5-2.0 $\mu \mathrm{m}$ as shown in Fig. 6(a), namely, smaller than that of the secondary iron particles. The secondary copper particles and silver sintered paste were almost separated. The interval between the secondary copper particles was very small. According to the characteristic X-ray spectrum shown in Fig. 6(b), only carbon was detected in the secondary copper particles.

\subsection{EDX Mapping}

The results of EDX mapping analysis of the laser-sintered iron nanopaste are shown in Fig. 7. The map shown was obtained before the surface of the laser sintered iron nanopaste was scraped. According to this result of EDX mapping, as shown in Fig. 7(b), the particles, which are sphere-like, are secondary iron particles. It has been found that the secondary iron particles and silver sintered paste are separated, as shown in Figs. 7(b) and (c).

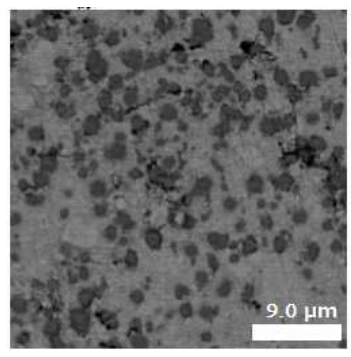

(a)

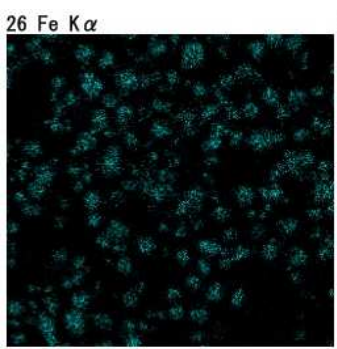

(b)

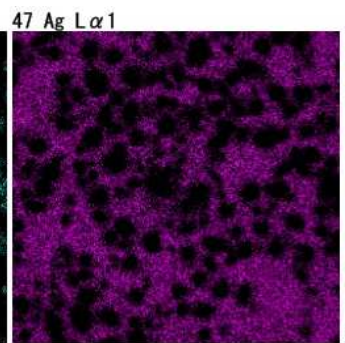

(c)
Fig. 7. Results of EDX mapping: (a) scattering image, (b) Fe, (c) Ag.
Silver particles move to the outer surface of the iron nanopaste when the nanopaste is sintered. The secondary iron particles remain at the center of the sintered iron nanopaste in the direction of the thickness. After sintering, the sintered silver paste was removed from the sintered nanopaste.

Carbon is a component of the silver nanopaste, and the EDX analysis showed that carbon are scattered near the sintered silver nanopaste, and the oxygen was attached to the outer surface of the secondary iron particles. The laser-sintered aluminum and copper nanopaste were also analyzed by EDX mapping. The results of EDX mapping analysis for aluminum and copper nanopaste were the same as those for Fe paste.

\subsection{Evaluation of Volume Resistivity}

The resistance and volume resistivity of all the sintered metal nanopastes were evaluated by the four-terminal method. The results are listed in Table 1 . The volume resistivity of the laser-sintered metal nanopastes are compared to that of common metal bulks. The resistivity was calculated by measuring the voltage and current per centimeter. The resistance was evaluated at $298 \mathrm{~K}$. In fact, after laser irradiation, although the sintered metal nanopastes had slight distortions on the surface, the distortion was neglected when volume resistivity was estimated. The thickness of the metal pastes was taken as $50 \mu \mathrm{m}$ in the calculation.

The volume resistivity of the laser-sintered metal nanopastes were also compared to that of the hot-plate sintered metal nanopastes. Spatial metal nanopastes were also synthesized. The nanopastes with reduced-metal nanoparticles were prepared by adding silver nanopaste to glycerin to reduce the quantity of the silver nanopaste used.

Table 1. Evaluated resistance and volume resistivity [18]

\begin{tabular}{|c|c|c|}
\hline Materials & $\begin{array}{l}\text { Resistance } \\
(\Omega)\end{array}$ & $\begin{array}{c}\text { Volume resistivity } \\
\left(\Omega \mathrm{m} / \mathbf{1 0}^{-8}\right)\end{array}$ \\
\hline Ag nanopaste ( Fig.3(a) ) & 0.020 & 70 \\
\hline Cu nanopaste ( Fig.3(c)) & 80 & $2 \times 10^{5}$ \\
\hline Bulk Fe (293K) & - & 10 \\
\hline Fe nanopaste (Ag paste) & 0.028 & 98 \\
\hline $\begin{array}{l}\text { Fe nanopaste } \\
\text { (Ag paste and glycerin) }\end{array}$ & 0.32 & 1120 \\
\hline Laser sintering ( Fig.3(d) ) & 0.027 & 94.5 \\
\hline Bulk Al (293K) & - & 2.65 \\
\hline Al nanopaste (Ag paste) & 0.002 & 7 \\
\hline $\begin{array}{l}\text { Al nanopaste } \\
\text { (Ag paste and glycerin) }\end{array}$ & 0.01 & 40 \\
\hline Laser sintering ( Fig.3(e) ) & 0.032 & 77 \\
\hline Bulk Cu (293K) & - & 1.68 \\
\hline $\mathrm{Cu}$ nanopaste (Ag paste) & 0.002 & 7 \\
\hline $\begin{array}{l}\text { Cu nanopaste } \\
\text { (Ag paste and glycerin) }\end{array}$ & 0.016 & 56 \\
\hline Laser sintering ( Fig.3(f) ) & 0.022 & 77 \\
\hline Bulk Mg (293K) & - & 4.42 \\
\hline Mg nanopaste (Ag paste) & 0.017 & 51 \\
\hline Laser sintering & 0.048 & 144 \\
\hline
\end{tabular}


All measured resistances per centimeter of metal nanopaste before sintering were very high (i.e., over $10 \mathrm{M} \Omega$ ). All measured resistances of the sintered metal nanopastes are reduced to $0.3 \Omega$. This result shows that all the sintered metal pastes are metalized. The resistance of the aluminum and copper nanopastes sintered by hot plate were single order and lower than that of commercial silver nanopaste. It is thus concluded that the resistance is not determined by the sintered silver nanopastes but by the sintered iron, aluminum, copper, or magnesium nanopastes.

In this experiment, the metal nanopaste was thick, and its outer surface contacts air; consequently, the temperature of the metal nanopastes should degrade slightly during sintering, thereby increasing of the resistance of the nanopaste.

The resistance of the sintered metal nanopastes is higher than that of common bulk metals owing to the boundary between the secondary metal particles. The high resistance is thought not to be due to the impurities. The metal nanopastes sintered by hot plate have 2.5- to 11-times-higher resistivity than those of common metals fabricated in blast furnaces. However, the laser-sintered metal nanopastes have 9.5- to 45-times-higher resistivity than those of such common metals. In the case of the laser-sintered iron nanopaste, its resistance is almost the same as that of the iron nanopaste sintered by hot plate. It is clear from the result that the iron nanopaste was sintered uniformly because its thermal conductivity is one order lower than that of aluminum, copper, and silver and because the iron nanopaste was heated at a higher temperature. However, the sintered aluminum, magnesium, and copper nanopastes made by adding silver nanopaste to glycerin have single-order higher resistances than that of the nanopastes made by adding silver nanopaste to reduced metal nanoparticles. It is thought that carbon affects the resistance or the sintered metal nanopastes are slightly oxidized.

In the case of the laser-sintered aluminum, copper, and magnesium nanopastes, their resistances are one order higher than those of the aluminum, magnesium, and copper nanopastes sintered by hot plate. In the case of sintering aluminum, magnesium, and copper nanopastes, it has been recognized that the nanopastes ware sintered non-uniformly because their thermal conductivities are around five times higher than that of iron, and the aluminum, copper, and magnesium nanopastes were heated at a lower temperature owing to heat loss by thermal conduction.

The resistance seems to be low in the direction of the laser scan owing to the uniformity of the high temperature generated by laser heating. The obtained volume resistivities are spatially averaged values. The local volume resistivities of the laser sintered aluminum, copper, and magnesium nanopastes, the parts at which the center of the laser beam was irradiated, should be adequately as low as that of the aluminum, copper, and magnesium nanopastes sintered by hot plate.

Because these resistance are between 0.002 and $0.32 \Omega$, these sintered metal nanopastes will be applicable to small-scale electrical circuits or electrical wire bonding. However, they will not be applicable to large-scale electrical circuits due to their high resistance.

The way to improve the sintering method is summarized as follows.

1) Uniform sintering and lower resistance

In the instrument used for laser sintering, a laser beam with a long and narrow square profile should be used to sinter a metal nanopaste with a large area.

2) Preparing more pure metals

Silver nanoparticles in the prepared metal nanopastes can be melted and deposited by using some heating instruments, and iron, aluminum, copper, and magnesium metal plates containing less silver can be obtained. Moreover, heating the metal plates for annealing will lower their resistances close to those of the respective common metal bulks.

\section{Conclusions}

Nanopastes with reduced iron, aluminum, copper, and magnesium nanoparticles were prepared. Commonly, these metals are easy to oxidize, and it has been hard to sinter metal nanopastes with their nanoparticles by using conventional methods. The nanopastes were sintered by using a CW fiber laser in air. The structures of the nano-polycrystalline pastes were analyzed by EDX and SEM. A large amountof secondary metal particles (with diameter of $0.5-2 \mu \mathrm{m}$ ) was observed in the laser-sintered metal pastes. Normally, the conventional color of copper is pale red, but that of the laser-sintered copper nanopaste was close to that of normal metals. The metal nanopastes sintered by hot plate have 2.5 to 11 times higher resistivities than those of common metals fabricated in blast furnaces. Moreover, the laser-sintered metal nanopastes have 9.5 to 45 times higher resistivities than those of common metals fabricated in blast furnaces. The resistivities of the laser-sintered metal pastes are adequately low for utilization of the nanopastes in electrical circuits. The sintering method as shown in this paper using a laser irradiation system should be modified in the future to obtain lower resistivity and fabricate large-scale metal plate or bulk.

\section{References}

[1] C. Deckard, "Method and apparatus for producing parts by selective sintering", U.S. Patent 4,863,538, filed Oct. 17, 1986, published Sep. 5, 1989.

[2] A. L. Dearden, P. J. Smith, D. Y. Shin, N. Reis, B. Derby and P. Brien, "A low curing temperature silver ink for use in ink-jet printing and subsequent production of conductive tracks", Micronol. Rapid Commun., Vol. 26, pp.315-318, 2005.

[3] J. W. Chung, S. H. Ko, N. R. Bieri, C. P. Grigopoulos and D. Poulikakos, "Conductor micro structures by laser curing of printed gold nanoparticle ink", Appl. Phys. Let., Vol. 84, pp. 801-803, 2004.

[4] J. Lee, B. Lee, S. Jeong, Y. Kim, "Microstructure and electrical property of laser-sintered Cu complex ink", Appl. Surf. Sci., Vol. 307, pp.42-45, 2014. 
[5] E. Halonen, E. Heinonen, M. Mäntysalo, "The effect of laser sintering process parameters on $\mathrm{Cu}$ nanoparticle ink in room conditions", Opt. and Photonics J., Vol. 3, pp.40-44, 2013.

[6] M. Zenou, O. Ermak, A. Saar and Z. Kotler, "Laser sintering of copper nanoparticles", J. Phys. D: Appl. Phys., Vol. 47, $025501-1-11,2014$.

[7] A. Henglein, "Physicochemical properties of small metal particles in solution: "microelectrode" reactions, chemisorption, composite metal particles, and the atom-to-metal transition," J. of Phys. Chem. B, Vol. 97, pp.5457-5471, 1993.

[8] M. S. Sibbald, G. humanov, and T. M. Cotton, "Reduction of cytochrome c by halide-modified, laser-ablated silver colloids," J. of Phys. Chem. B, Vol. 100, pp. 4672-4678, 1996.

[9] T. Sasaki, Y. Shimizu, N. koshizaki, "Preparation of metal oxide-based nanomaterials using nanosecond pulsed laser ablation in liquids", $\mathrm{J}$ of Photochem. and Photobiol. A: Chem., Vol. 182, pp.335-341, 2006.

[10] M. Kawasaki, "Laser-induced fragmentative decomposition of Fine $\mathrm{CuO}$ powder in acetone as highly productive pathway to $\mathrm{Cu}$ and $\mathrm{Cu} 2 \mathrm{O}$ nanoparticle", J. of Phys. Chem. C, Vol. 115, pp.5165-5173, 2011.

[11] K. Yamada, K. Miyajima, and F. Mafune, "Ionization of gold nanoparticles in solution by pulse laser excitation as studied by mass spectrometric detection of gold cluster ions", J. of Phys. Chem. C, Vol. 111, Article ID 033401, 2007.

[12] T. Saiki, T. Okada, K. Nakamura, T. Karita, Y. Nishikawa, and Y. Iida, "Air cells using negative metal electrodes fabricated by sintering pastes with base metal nanoparticles for efficient utilization of solar energy", Int. J. of Energy Sci., Vol. 2, No. 6, pp. 228-234, 2012.

[13] T. Saiki, S. Uchida, T. Karita, K. Nakamura, Y. Nichikawa, S. Taniguchi Y. Iida, "Recyclable air fuel cells using sintered $\mathrm{Mg}$ nanopastes for solar energy cycle", Proc. the 3rd Advanced Lasers and Photon Sources Conference (ALPS), pp.161-162, Yokohama, Japan, Apr. 24, 2014.

[14] T. Saiki, M. Nakatsuka, K. Imasaki, "Highly efficient lasing action of $\mathrm{Nd} 3+-$ and $\mathrm{Cr} 3+-$ doped yttrium aluminum garnet ceramics based on phonon-assisted cross-relaxation using solar light source", Jpn. J. App. Phys., Vol. 49, 082702-1-8, 2010 .

[15] T. Okada, T. Saiki, S. Taniguchi, T. Ueda, K. Nakamura, Y. Nishikawa, and Y. Iida, "Hydrogen production using reduced-iron nanoparticles by laser ablation in liquids", ISRN Renewable Energy, Vol. 2013, 827681-1-7, 2013.

[16] A. H. Chokshi, A. Rosen, J. Karch, and H. Gleiter, "Diffusional creep of a SiC whisker reinforced Alumina/Zirconia composite", Scripta Metall., Vol. 23, pp.1679-1683, 1989.

[17] G. Palumbo, S. J. Thorpe, and K. T. Aust, "On the contribution of triple junctions to the structure and properties of nanocrystalline materials" Scripta Metall. Mater., Vol. 24, pp. 1347-1350, 1990 .

[18] National Astronomical Observatory (ed.) : "Rika Nenpyo", p.482, Maruzen, Tokyo (2000). 